\title{
A CULTURA E 0 NOVO MUNDO NOVO
}

\author{
Isabel Pires de Lima \\ Universidade do Porto \\ Instituto de Literatura Comparada \\ Margarida Losa
}



A cultura, como ben se sabe, ten unha multiplicidade de acepcións. No sentido máis lato, abrangue todas as actividades, formas e estratexias dunha poboación, as prácticas cotiás, as actividades produtivas e as de lecer, a relación coa terra e co clima, os valores, as crenzas, os usos e os costumes, as tradicións, os testemuños patrimoniais de xenio e creatividade na historia e na actualidade...

Neste sentido, todo na vida trae a marca da cultura á que pertencemos e é inseparable desta. Mesmo cando algún ou algúns de nós afirman, en maior ou menor medida, unha individualidade que entra en conflito con ela, certo é que, mesmo neses casos, non se perde a relación de pertenza, que ten que ser entendida nunha perspectiva dialéctica e dinámica. Todas as culturas están en movemento e en transformación permanentes. Todas dialogan co pasado e transportan o futuro. $\mathrm{E}$ todas son, ademais diso, por natureza, interculturais, e reafirman as súas respectivas identidades no diálogo e no mutuo troco de experiencias ou influencias.

Mais hai unha outra acepción de cultura, de sentido máis estrito, que se refire ao chamado sector cultural e na que cabe o chamado patrimonio inmaterial (constituído pola lingua, polos seus dialectos e polas tradicións etnográficas e antropolóxicas), a paisaxe cultural, o patrimonio histórico edificado, o patrimonio móbil e documental (conservado nos museos, as bibliotecas, as cinematecas e os arquivos), e, é claro, todo aquel conxunto diversificado de actividades de creación, comunicación, difusión e recepción ligadas ás diferentes artes: literatura, música, teatro, danza, cinema e audiovisual, artes plásticas, arquitectura, deseño, artes chamadas dixitais e manifestacións híbridas ou eclécticas transversais a varias delas.

Agora ben, o sector cultural atravesa profundas transformacións que derivan tanto da propia dinámica de creatividade que lle é intrínseca como, de igual modo, da rápida evolución tecnolóxica e do respectivo impacto exercido na produción e na difusión de bens culturais, e está a gañar consciencia da súa importancia económica crecente e a constatar a relevancia de contribuír a unha maior 
percepción pública e visibilidade de todo canto representa en canto factor de desenvolvemento das sociedades contemporáneas.

Deixouse de poder ollar para a cultura só nas súas dimensións espiritual e lúdica. Hoxe, a cultura require un ollar multifacético e transversal que é simultaneamente político, social e económico. Político, porque no seo da cultura se desenvolven ideas e movementos que mudan as sociedades. Social, porque é na cultura onde os pobos encontran a súa identidade e, a través do diálogo e do coñecemento mutuo, descobren o encontro e a comuñón de valores cos que cimentan a cohesión de grupo e os sentimentos de pertenza. Económico, porque as actividades culturais e creativas son, desde logo, a primeira fonte creadora de innovación, hoxe esencial na capacidade de produción e competitividade.

En suma, cada vez máis a cultura representa un eixe fundamental no desenvolvemento e na definición das estratexias económicas, sociais, tecnolóxicas e educativas que teñen como obxecto estimularen a produción de contidos creativos innovadores, os cales representan hoxe un crucial factor xerador de riqueza e competitividade.

Por todo isto hai xa bastante consenso sobre a idea de que a cultura non é aquilo de que se debe tratar cando todo o resto, tido como prioritario para o desenvolvemento, xa está tratado, o ramo que se lle pon á obra, para pasar a ser entendida como un factor angular de progreso social e económico. Na súa dupla dimensión de creación e de fruición pasou a ser encarada como promotora da apertura das poboacións a novos coñecementos e a outras realidades, xerando masa crítica, esencial para a transformación ou a cualificación, ou ambas, do tecido económico e social.

En suma, a cultura fortalece a identidade, afirma as diferenzas locais e nacionais, defende un patrimonio físico, lingüístico e inmaterial e, simultaneamente, proxéctase para o outro cando resulta revitalizada pola experiencia da contemporaneidade. E tamén por esta vía a cultura é mobilizadora da innovación.

É que a capacidade de competir e prosperar nos tempos presentes na economía global xa non se basea, como no pasado, nos recursos naturais e no capital físico, senón cada vez máis na creatividade humana e na habilidade das nacións para atraeren, reteren e proporcionaren a expresión de persoas creativas. Para moitos especialistas, como Richard Florida, a competitividade futura vai depender dos chamados «3 T» do crecemento económico: tecnoloxía, talento e tolerancia. 
- A tecnoloxía é elemento central pola súa función de concentración de innovación, que xera progreso tecnolóxico e crecemento a longo prazo.

- O talento é importante porque reflicte a existencia de recursos humanos capacitados para os desafíos da innovación e da produtividade a medio e longo prazo, os cales requiren de competencias creativas.

- A tolerancia, no sentido de apertura e capacidade de diálogo coas diferenzas do Outro, afecta á posibilidade das nacións e das rexións de mobilizaren a súa propia capacidade de creatividade e de competiren en termos de talento creativo. Canto máis aberta e inclusiva for unha cidade, rexión ou nación, máis doado será atraer talento. Un premio Nobel de Economía como Robert Lucas hai moito que defende que o crecemento económico provén dos clusters de talento cultural e de elevado capital humano. Atraer e reter talentos conduce á produción de novas ideas, de innovación e de empresas emprendedoras que lideran o crecemento económico. E a capacidade de atracción de talento é proporcional á capacidade de apertura á diversidade e á tolerancia.

Un estudo encomendado pola Comisión Europea sobre a economía da cultura (dous termos que raramente aparecían conxugados até mediados desta década) e publicado a finais de 2006 revelou algunhas cifras sorprendentes de cuantificación da repercusión socioeconómica dos sectores creativo e cultural na Unión Europea: en 2003 (UE 25), a economía da cultura representou o 2,6\% do PIB europeo ( $5 \%$ nos países máis desenvolvidos: Francia ou o Reino Unido, por exemplo; $1,4 \%$ en Portugal), isto é, máis ca o sector do automóbil, ca o sector inmobiliario, ca o sector téxtil; entre 1999 e 2003 a economía da cultura creceu un 19,7\%, é dicir, un $12,3 \%$ máis que a taxa media de crecemento; en 2004 empregaba cerca de 6 millóns de persoas, o que se corresponde co 3,1\% do emprego na entón Europa dos 25 e co crecemento, entre 2002 e 2004, de case un 2\%, nun cadro de recesión do emprego. Este estudo, importa lembralo, abrangue o sector cultural tradicional, chamémolo así (artes visuais e escénicas, patrimonio moble e inmoble), as industrias da creación (cinema, vídeo, radio e televisión, videogramas, música, libro e prensa), actividades creativas (entre outras, o deseño e a arquitectura) e o impacto do sector cultural no desenvolvemento das industrias con el relacionadas, como o turismo cultural e as industrias TIC (computadores, MP3).

Hai que advertir, no entanto, que pola fin de 2009 o Ministerio de Cultura de Portugal publicou un estudo fundamentado en datos moito máis precisos, no 
que se refire ao caso portugués, sobre a situación do sector cultural e creativo en Portugal en 2006, o cal revela que este contribuíu co 2,8\% ao total da riqueza creada nese ano (superior, tamén aquí, ás industrias da alimentación e das bebidas ou ao sector téxtil e de vestiario). Evidencia este estudo, así mesmo, que entre 2000 e 2006, nun cadro xeral de crecemento do emprego da orde de só 0,4\%, no sector cultural o emprego aumentou un 4,5\% (máis, por exemplo, que no sector inmobiliario).

Nas súas conclusións, ao analizar o papel da cultura no ámbito dos obxectivos da «Estratexia de Lisboa para a competitividade, o crecemento e o emprego", que foi aprobada en 2001, o referido estudo europeo subliña a especial importancia da achega cultural á innovación, o emprego e a competitividade.

Ora ben: nun mundo sistémico como este en que vivimos, todo está interrelacionado e a innovación, en calquera sector da economía, require dunha base de creatividade dentro do proceso conxugado das ideas, aptitudes, tecnoloxías e procesos de xestión, de organización e de produción. E neste proceso complexo a cultura ocupa un lugar relevante na medida en que a través dela ou nela se educa, se libera e se promove a proxección do futuro, a imaxinación e a sensibilidade na abordaxe de problemas e solucións. Aínda máis, a neurociencia veu acentuar a vertente de anticipación da creatividade, a súa vertente exploratoria. Recentemente, o neurocientífico norteamericano e aínda mozo Jonah Lehrer mostrou, nun libro que coñeceu un grande éxito titulado Proust Was a Neuroscientist («Proust era neurocientífico»), como, a través de camiños peculiares, grandes artistas da palabra, das liñas e da cor, dos sons ou de dominios máis inesperados como a gastronomía, nas súas creacións, expresaran o que ningunha experiencia fora capaz de ver antes. E móstrao en creadores tan diversos como Walt Whitman, Paul Cézanne, Igor Stravinsky ou, claro está, Marcel Proust.

Ademais diso, a cultura promove emprego cualificado -o mesmo estudo mostraba que en 2004, no emprego cultural radicado no seo da UE, o 46,8\% tiña un grao académico superior contra un 25,7\% nos restantes sectores- na medida en que non só fomenta en por si esa cualificación, senón que tamén suscita, na vertente económica do sector, o emprego dun crecente número de traballadores e de axentes culturais (sexan participantes individuais, sexan pequenas e medianas empresas ou outras entidades colectivas asociativas ou de utilidade pública). 
E porque a cultura promove un enriquecemento da civilización, unha melloría dos patróns de coñecemento e ata un equipamento técnico, podemos dicir que ademais contribúe decisivamente á empregabilidade ao permitir ampliar o corpo de ideas, saberes, aptitudes e competencias de cada persoa activa no mercado de traballo e de cada rapaz que nese mercado pretende entrar por vez primeira, fomentando simultaneamente a capacidade emprendedora. A este respecto, o estudo de que vimos falando revela que a porcentaxe de traballadores independentes na área de cultura era en 2004 dúas veces superior ao da totalidade do emprego. Polo demais, o emprego cultural presenta unha natureza atípica que, para moitos observadores, sinala as características do emprego do futuro: flexibilidade, orientación por proxectos e necesidade de mobilidade e elevados patróns de habilitacións e formación.

Hase de notar, ademais, que, no ámbito das habilitacións e da formación, o mesmo estudo sinala que as ocupacións do sector cultural e creativo requiren cada vez máis, para alén do talento e de aptitudes artísticas, de novas aptitudes e competencias técnicas e de xestión; unha observación especialmente importante ante outra característica: o crecente número de pequenas empresas neste sector. Nun mercado de bens e servizos cada vez máis competitivo, xa non abonda con atender os dous parámetros tradicionais: prezo e tecnoloxía. Agora a competitividade pasa fundamentalmente pola diferenciación e pola calidade deses bens e servizos. E esta dimensión inmaterial é xerada por empresas e traballadores dotados de creatividade, unha creatividade á cal contribúe decisivamente a educación artística e cultural e que terá que continuar a alimentarse, ao longo da vida, da cultura a través das súas máis diversas manifestacións.

O estudo da Comisión Europea sobre a economía da cultura constituíu, máis que unha moi útil base de traballo, un instrumento estratéxico de demostración do que o sector representaba para acadar os obxectivos da Estratexia de Lisboa e, consecuentemente, representa hoxe para Europa encontrar o seu propio camiño na superación da crise. De feito, como consecuencia inmediata asistiuse por vez primeira, nos cincuenta anos de historia da Unión Europea, á publicación dunha comunicación da Comisión Europea sobre cultura que propuña a creación en 2007 dunha Axenda Europea da Cultura. Aí faise a identificación de prioridades compartidas, inspiradas polos valores que son comúns aos europeos, como a diversidade cultural e lingüística, o diálogo permanente co Outro ou a 
liberdade de expresión e de creación, debendo ter incidencia sobre a vertente económica da cultura mais tamén sobre o seu aspecto simbólico e de factor de pertenza a unha comunidade, e asegurar, de igual modo, un poder mobilizador para outras políticas comunitarias e unha vocación transversal.

Que quere dicir isto entón? Que se abren grandes oportunidades para a cultura - un novo mundo novo- no seo da Unión Europea e que por vez primeira se procura esbozar algunhas liñas de acción política común e se acepta algunha coordinación entre os países membros en materia de política cultural, o que implica troco e comparabilidade das boas prácticas.

Mais, por outro lado, é preciso continuar a ser ben consciente de que a cultura e a creatividade non deben ser reducidas á categoría de motores de crecemento económico e de que o seu alcance supera largamente os vectores cuantificables en cifras ou indicadores de competitividade. Teñen unha especificidade que non deben deixar de reclamar decontino. António Damásio, un dos grandes nomes da neurociencia mundial, nunha conferencia da UNESCO realizada en 2006 en Lisboa, salientaba, a propósito da necesidade de fortalecer a educación artística para a construción dunha sociedade máis inclusiva, que as narrativas sociais e éticas, fundamentos dos valores de que as prácticas sociais contemporáneas han de andar faltas, só se poden exercitar de maneira cabal a través das ciencias sociais e das artes. Son exactamente estas especificidades as que deben conducir á defensa do principio das políticas públicas de apoio ás artes e á salvagarda e á revitalización do patrimonio.

Por todo isto importa o seguinte:

1) concibir e elaborar instrumentos de comunicación que permitan estimular a crecente expansión das redes de intercambio e de cooperación, das redes de interacción, dado que os varios sectores de actividade son hoxe cada vez máis interdependentes uns dos outros no seu desenvolvemento;

2) incentivar medios de apoio ao reforzo de competencias, transferencia de tecnoloxía e aptitudes;

3) fomentar e facilitar o espírito emprendedor.

A propósito disto, as industrias creativas xa teñen un impacto significativo nas taxas de crecemento e, igualmente, unha enorme potencia de crecemento engadido que pode ser usado para crear novas oportunidades. Isto obriga a recoñecer a súa natureza específica e a artellar un novo pensamento estratéxico de 
desenvolvemento por parte dos poderes locais, rexionais e nacionais e por parte da sociedade civil -axentes culturais, empresarios, mecenas. Hoxe, por iso mesmo, nas sociedades máis dinámicas economicamente, a sociedade civil contribúe decisivamente de modo organizado ás políticas da cultura, incluídas as públicas, participando non só no seu financiamento, mais tamén na propia estruturación das redes de oferta cultural e na cualificación e a salvagarda dos seus contidos, quer esteamos a falar de políticas de produción artística contemporánea, quer de políticas patrimoniais de preservación.

A especificidade dunha cultura local, rexional ou nacional, relacionada coa paisaxe, o ambiente, o patrimonio material e inmaterial, os equipamentos e as actividades artísticas, o tecido doutras actividades produtivas (agrícolas, industriais ou comerciais), etc. -a capacidade de articular e potenciar o conxunto desas dimensións nun todo harmonioso-, constitúe hoxe o capital máis relevante do desenvolvemento. Esta visión de rede, na cal se parte da idea de cualificar o local ou a rexión para que se transformen en destinos máis atractivos, quer para vivir, quer para visitar, é fundamental na actualidade en calquera estratexia de desenvolvemento. Nos nosos días, por exemplo, admítese a importancia das estratexias deste tipo centradas na abordaxe das «cidades creativas» e do papel que estas poden ter na expresión e na valorización da identidade e da cultura locais de cada espazo urbano, ao igual que no fortalecemento de dinámicas de promoción da competitividade e do emprego. Recoñécese o espazo urbano como palco privilexiado de execución das actividades culturais e creativas, en particular daquelas máis innovadoras e das que configuran dinámicas culturais máis sustentables e o papel determinante que as actividades culturais teñen na promoción do desenvolvemento e a competitividade dos espazos urbanos, por múltiples vías (a creación de riqueza económica e de emprego; a configuración de lóxicas de participación, de inclusión social e da expresión multicultural; a posibilidade de se asociaren a lóxicas de rexeneración urbana e de recualificación ambiental; a propia dimensión da expresión cultural e de identidade que estas prácticas configuran, etc.).

Compréndese que todas estas mudanzas que se configuran no sector da cultura levan a encarar dun modo novo as estreitas relacións, xeradoras de enormes sinerxías, que se dan non só entre economía e cultura ou industrias creativas e cultura, mais tamén entre educación e cultura, entre turismo e cultura, entre 
diplomacia e cultura, maiormente no marco da Unión Europea. Isto é, ábrese para a cultura un novo mundo novo.

A ligazón existente entre cultura e turismo é outro aspecto moi visible da contribución da cultura ao desenvolvemento local e rexional e que para a Península Ibérica, que ten na industria turística unha das súas principais fontes de riqueza, se revela como prioritario. Paga a pena lembrar que se encontran en Europa os destinos turísticos máis visitados do mundo. En 2005, o continente europeo rexistrou cerca de 450 millóns de visitantes atraídos por unha Europa que ten a máis alta densidade de patrimonio cultural (por exemplo, preto do $40 \%$ dos lugares designados Patrimonio Mundial da UNESCO están situados en Europa).

O esforzo de restauración e preservación do patrimonio por toda Europa foi ata agora, polo demais, un excelente investimento, representando un instrumento importante para contribuír á atractiva oferta de diversidade cultural europea e ao desenvolvemento de infraestruturas de apoio.

Non hai estatísticas precisas sobre turismo exclusivamente cultural, mais paga a pena referir que o sector do turismo xera o 5,5\% do PIB europeo e emprega cerca de nove millóns de persoas. Así como pagará tamén a pena lembrar que o turismo europeo terá inevitablemente, cada vez máis, unha vocación cultural fronte á oferta cada vez maior e máis diversa de turismo de sol e praia en espazos exóticos extraeuropeos.

En función da oferta cultural, o turismo cultural está intimamente asociado á visibilidade das cidades. Non se trata só de patrimonio. Importa subliñar o papel desempeñado nesta oferta polas feiras culturais, as exposicións temporais, os festivais de artes escénicas, etc. $\mathrm{O}$ turismo cultural xera ingresos significativos e ten relevantes efectos económicos indirectos. Sen esquecer a contribución para alimentar a permanente base local do desenvolvemento cultural en virtude da participación da poboación da zona e da crecente capacidade local para producir a oferta de bens e servizos requiridos pola procura e a interdependencia de todas esas actividades, para así forxar o efecto de cluster. Este é tamén un sector en que as oportunidades son innumerables na Península Ibérica, e no cal aprema crear máis oferta turística cultural.

Unha última e breve palabra sobre un papel simbólico da cultura que fai dela un instrumento precioso da diplomacia. A cultura revélase, ademais, como un 
claro factor de facilitación no contacto cos outros pobos e ten, por iso, un recoñecido papel no apoio á diplomacia e ao desenvolvemento dos intereses comerciais do país. É polo cultural como os pobos se coñecen, eliminan os mutuos receos do descoñecido e relativizan as barreiras de identidade que poidan oporse á súa aproximación e ao establecemento ou á consolidación de relacións políticas e comerciais. Ao non estar na primeira liña das realidades políticas xeoestratéxicas, a cultura ofrece mesmo terreos e medios de aproximación ou de reaproximación dentro dos cales se establecen frecuentemente os primeiros ou renovados contactos bilaterais e se crea o ambiente político máis propicio para o florecemento de relacións máis profundas.

Pola cultura coñécese o Outro e interprétanse e desvélanse os códigos de comunicación dos nosos interlocutores. Pola cultura presentámonos perante o Outro para tornarnos en interlocutores. Pola cultura entendémonos e relacionámonos. Se, en tempos, a actividade se entendía fundamentalmente como unha canle privilexiada de comunicación política, hoxe en día, recoñecida a importancia das relacións comerciais, a diplomacia asumiu a integración das consideracións económicas no seu ambiente. $\mathrm{E}$, por iso, a diplomacia admite cada vez máis a forma en que a cultura representa a tarxeta de visita, a primeira impresión, a imaxe do país que se presenta, o perfil que sabe ter e que desexa ver recoñecido na diferenciación competitiva. A ela recorre non en última instancia, senón polo acceso que proporciona ao necesario diálogo.

Ora ben, este diálogo, nos difíciles tempos que corren na escena internacional, é especialmente necesario. As sociedades modernas, caracterizadas por movementos migratorios, son cada vez máis sociedades multiculturais que requiren da achega da comprensión e do diálogo cultural para a súa cohesión. $\mathrm{E}$, nun mundo globalizado, tamén esa comprensión mutua e ese diálogo intercultural se tornan en necesarios para impedir que se volvan erguer barreiras entre sociedades culturalmente diferenciadas que, aínda así, poden e deben coexistir na paz proporcionada polo coñecemento e as vantaxes mutuos das súas relacións políticas e económicas. A diplomacia recoñéceo e fai hoxe da cultura un dos máis activos piares da política exterior; outro espazo, este, de oportunidades da cultura, que xa abertamente se denomina diplomacia cultural.

En resumo, é, pois, de primordial importancia desenvolver unha nova e máis ambiciosa abordaxe do sector cultural, alicerzada en estratexias integradas e 
coordinadas que reforcen a súa ligazón efectiva ao mundo real. As políticas da cultura están destinadas a gañar máis espazo e coherencia na gobernación europea, e os indicadores económicos, as estatísticas dispoñibles e os indicios políticos apuntan nese sentido.

Creatividade é innovación. Innovación é competitividade. Competitividade é negocio produtivo. Negocio produtivo é emprego. Emprego é posibilidade de benestar. Benestar é ocupación lúdica e espiritual. Así é a cultura no limiar do presente século: un novo mundo novo á nosa espera. Así, saibamos aproveitar e explorar a oportunidade en tempo de crise. 